\title{
Fairy Ring Disease of Cranberry: Assessment of Crop Losses and Impact on Cultivar Genotype
}

Peter V. Oudemans, Rutgers University, and James J. Polashock, United States Department of AgricultureAgricultural Research Service (USDA-ARS), Blueberry and Cranberry Research and Extension Center, Chatsworth, NJ 08019; and Bryan T. Vinyard, USDA-ARS, Biometrical Consulting Service, Beltsville, MD 20705

\begin{abstract}
Oudemans, P. V., Polashock, J. J., and Vinyard, B. T. 2008. Fairy ring disease of cranberry: Assessment of crop losses and impact on cultivar genotype. Plant Dis. 92:616-622.

Fairy ring is a disease of cultivated cranberry common in the eastern growing regions of the United States, especially New Jersey and Massachusetts. Rings may persist for many years, and current control recommendations are costly and largely ineffective. The goal of this study was to accurately assess the impact of this disease on cranberry, a long-lived, high-value, perennial crop. The rate of fairy ring expansion, rate of formation of new rings, and distribution of rings across three cultivars were determined using a geographical information system (GIS) database that incorporated aerial and satellite imagery. Ring growth rates, estimated from imagery collected over a 10-year period in cv. Ben Lear, averaged $0.455 \mathrm{~m}$ in radius per year. Rings were observed in 'Ben Lear' three times more frequently than in either 'Early Black' or 'Stevens' cultivars. Direct sampling showed that estimates for yield within rings were 22 to $68 \%$ less than unaffected areas of the field for cv. Ben Lear. These estimates included the effects of fruit rot, which was elevated within rings to 18 to $29 \%$ of the total harvest. The impact on yield of 'Stevens' and 'Early Black' was lower than in 'Ben Lear'. Most cranberry cultivars are clonal and variation in fruit morphology within rings, particularly in 'Ben Lear', prompted an analysis of vine genotype. Areas affected by fairy ring in 'Ben Lear' showed an increase in genetic diversity at least 0.4 to 4 times that of unaffected areas. Therefore, it appears that fairy ring not only directly reduces yield but also can increase the host genetic diversity. This likely is due to increased seedling establishment resulting from seed drop when fruit decompose. Because seedlings typically yield less than the parental cultivar, the increase in genetic diversity also may contribute to long-term reduction of productivity in a cranberry field.
\end{abstract}

Additional keywords: seed bank

Fairy ring of cranberry is an insidious disease with poorly defined long-term impacts on the productivity of infected fields. Recommended treatments for control of this disease include annual application of Ferbam (carbamate) at a rate of $0.43 \mathrm{~kg} / \mathrm{m}^{2}(12)$. Although treatments target symptomatic areas, this recommendation represents an extreme expense (approximately $\$ 25,000$ per treated hectare), and efficacy is variable. When the disease was first described, mushrooms of the species Psilocybe agrariella Atk. var. vaccinii $\mathrm{V}$. Charles were associated with some rings and assumed to be the causal agent, although other causal agents were not ex-

Corresponding author: P. V. Oudemans

E-mail: oudemans@ aesop.rutgers.edu

* The $\boldsymbol{e}$-Xtra logo stands for "electronic extra" and indicates that Figures 1 and 6 appear in color in the online edition.

Accepted for publication 16 November 2007.

doi:10.1094/PDIS-92-4-0616

This article is in the public domain and not copyrightable. It may be freely reprinted with customary crediting of the source. The American Phytopathological Society, 2008. been reports of Phialophora spp. associated with symptomatic plants (3), as well as Rhizoctonia-like fungi (2). Oudemans et al. (7) found isolates with high internal transcribed spacer sequence homology to the family Dermatataceae, including the genera Pezicula, Dermea, and Neofabrea. In all cases, pathogenicity tests have been inconclusive and identification of the causal agent requires further study. However, based on these observations, it is likely that fairy ring is a misnomer and the disease has more in common with the patch diseases of turf that often expand in ring-like formations.

A typical cranberry fairy ring begins with a necrotic zone where the crop plant is killed or at least debilitated by the pathogen (Fig. 1). As this necrotic zone expands, the area inside this zone opens up and becomes weedy. Over time, cranberry vines recolonize the open area, and the affected region of the field recovers. The outside edge of the necrotic zone is sometimes bordered by a ring of cranberry vine overgrowth. However, treatment of unaffected areas with carbamate caused a similar increase in vine growth (P. V. Oudemans, unpublished), suggesting the overgrowth is caused by the fungicide and not the disease. Outside of the overgrown zone are healthy vines that are cluded (10). Mushroom fruiting bodies have only rarely been associated with the disease, and it is possible that a different organism is the causal agent. There have

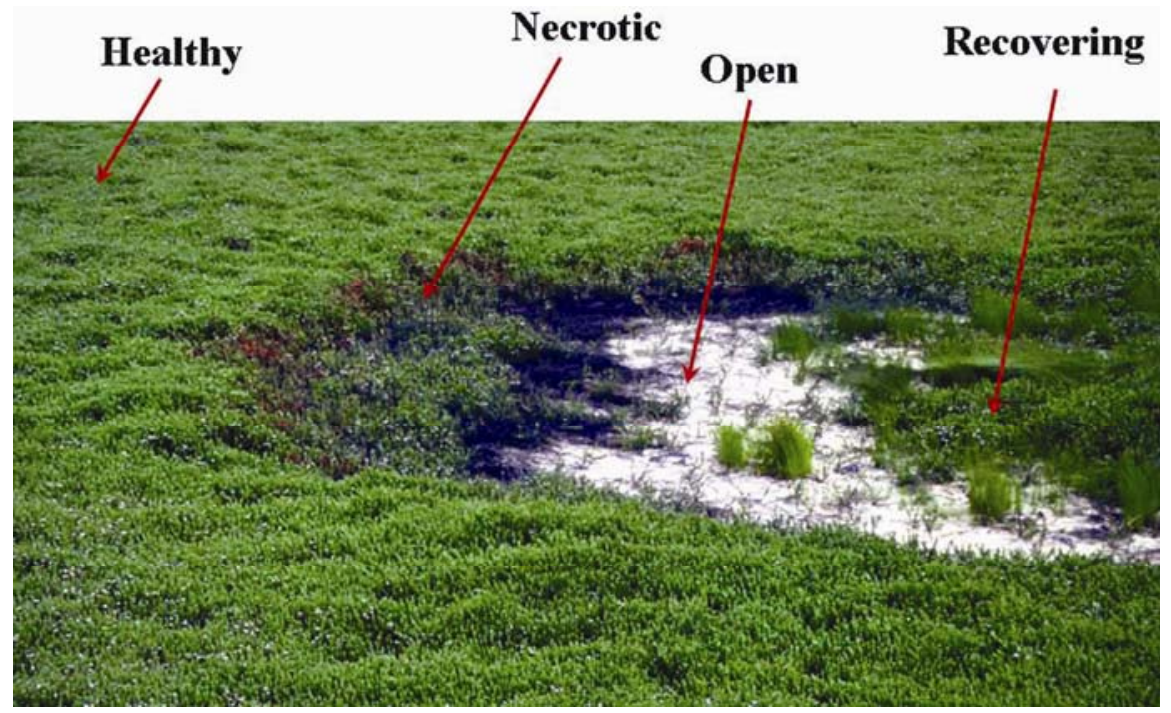

Fig. 1. Anatomy of a typical cranberry fairy ring. The pathogen kills vines as it advances across affected fields forming the necrotic zone (Necrotic). Inside the necrotic zone, an open area forms that becomes weedy and later fills in with cranberry vines (Recovering). Rings may be bordered by an overgrown area that blends into the healthy (Healthy), unaffected part of the field. 
not visibly affected by the advancing disease.

There is little information on the epidemiology of the disease. The mechanism for dissemination is unknown; however, Caruso (1) suggests that, when fields are flooded and berries removed by a specialized harvester, infected vines may be pulled up and transferred to other parts of the field, thus spreading the disease. Other observations indicate that new rings are often seen near drainage canals that typically surround cranberry fields, suggesting a different mechanism. There is no published information on the timing of disease spread. Zuckerman (12) reported that applications of carbamate in September were effective for controlling the disease. Unfortunately, no other timings were tested. Caruso (unpublished results) has found that fungicide applications near bud break are most effective whereas applications made later are progressively less effective. Without specific information on the causal agent, timing of infection remains difficult to establish.

Fairy ring traditionally was considered to be of minor importance (10). It usually was seen on older fields and, although the symptoms were obvious, the disease was shown to have a minor impact on yield (10). The rings were reported to enlarge at a rate of 0.30 to $0.45 \mathrm{~m}$ in diameter per year but disappeared after a few years (10). Over the past 50 years, cranberry productivity has increased 5- to 10-fold (4). This has been the result of improved crop management techniques as well as the planting of improved cultivars. Fairy ring has now emerged as an important consideration for cranberry producers because of laborintensive control methods, cost of materials, and potentially negative effects on yield. There are also anecdotal reports that fields affected by the disease exhibit a greater diversity of berry morphology. The impact of fairy ring on current cranberry crop production needs to be determined. Our objectives in this study were to (i) determine the rate of expansion and spread of fairy ring disease in cranberry; (ii) quantify yield effects of fairy ring infections on commercial producing cranberry acreage; (iii) compare the distribution, incidence, and severity of fairy ring on the three most common cultivars grown in New Jersey; and (iv) assess the degree and causes of indirect crop loss and determine whether progression of the disease affects host diversity.

\section{MATERIALS AND METHODS}

Study location. The study was conducted near Chatsworth, NJ during the period of 2000 to 2006. Within this study region, a single commercial cranberry field with 19 visible rings was identified and selected for detailed study. This field had been planted with cv. Ben Lear in 1989 and began commercial production in 1992 .
The field had no prior history of fairy ring control and, through agreement with the owner, no fairy ring management was implemented for the duration of this study. In 2006, a survey of fairy ring infestation was conducted over a larger area that included approximately 675 ha of cultivated cranberry. 'Early Black', 'Stevens', and 'Ben Lear' are the three most common cultivars grown in New Jersey and account for approximately $80 \%$ of the genotypes within this area.

Estimation of fairy ring area. Fairy ring perimeters were digitized from remote-sensed imagery. For comparison, measurements were made using global positioning system (GPS) and all the data were managed within ArcView 3.3 (ESRI, Redlands CA), a geographic information system (GIS) software package. On the ground, fairy rings were measured by walking the periphery of each ring using a Trimble Pro-XR GPS unit (Trimble Navi- gation Limited, Sunnyvale, CA) set to record points at 10 -s intervals. The data were imported from the GPS unit using Pathfinder Office (version 3.0; (Trimble Navigation Limited) and differentially corrected using the Trenton, NJ base station (http://www.state.nj.us/dep/gis/newgps.htm) as a reference. The vector information was exported to ArcView 3.3. This was conducted in 2000, 2001, and 2003 to 2006.

Several sources of remote sensedimagery were used as backdrops in the GIS database (Table 1). Commercial nearinfrared imagery was scanned at 1,200 dots per inch on a Microtek Scanmaker 9600XL flatbed scanner (Microtek USA, Carson, CA). The imagery was georeferenced to the UTM NAD83 coordinate system using ground control points and reprojected to a $60-\mathrm{cm}$ ground resolution using the ERDAS Imagine 9.0 software (Leica Geosystems, Heerbrugg, Switzerland). Satellite imagery (Table 1) was pur-

Table 1. Imagery available for the study area

\begin{tabular}{llcc}
\hline Imagery type & Years available & Pixel resolution $(\mathbf{m})$ & Fairy rings visible \\
\hline Scanned NIR aerial imagery & $1987,1989-2000$ & 0.6 & + \\
IKONOS, multispectral & $2000-2002$ & 4.0 & - \\
QuickBird, multispectral & $2003-2006$ & 2.4 & - \\
QuickBird, panchromatic & $2003-2006$ & 0.6 & + \\
\hline
\end{tabular}

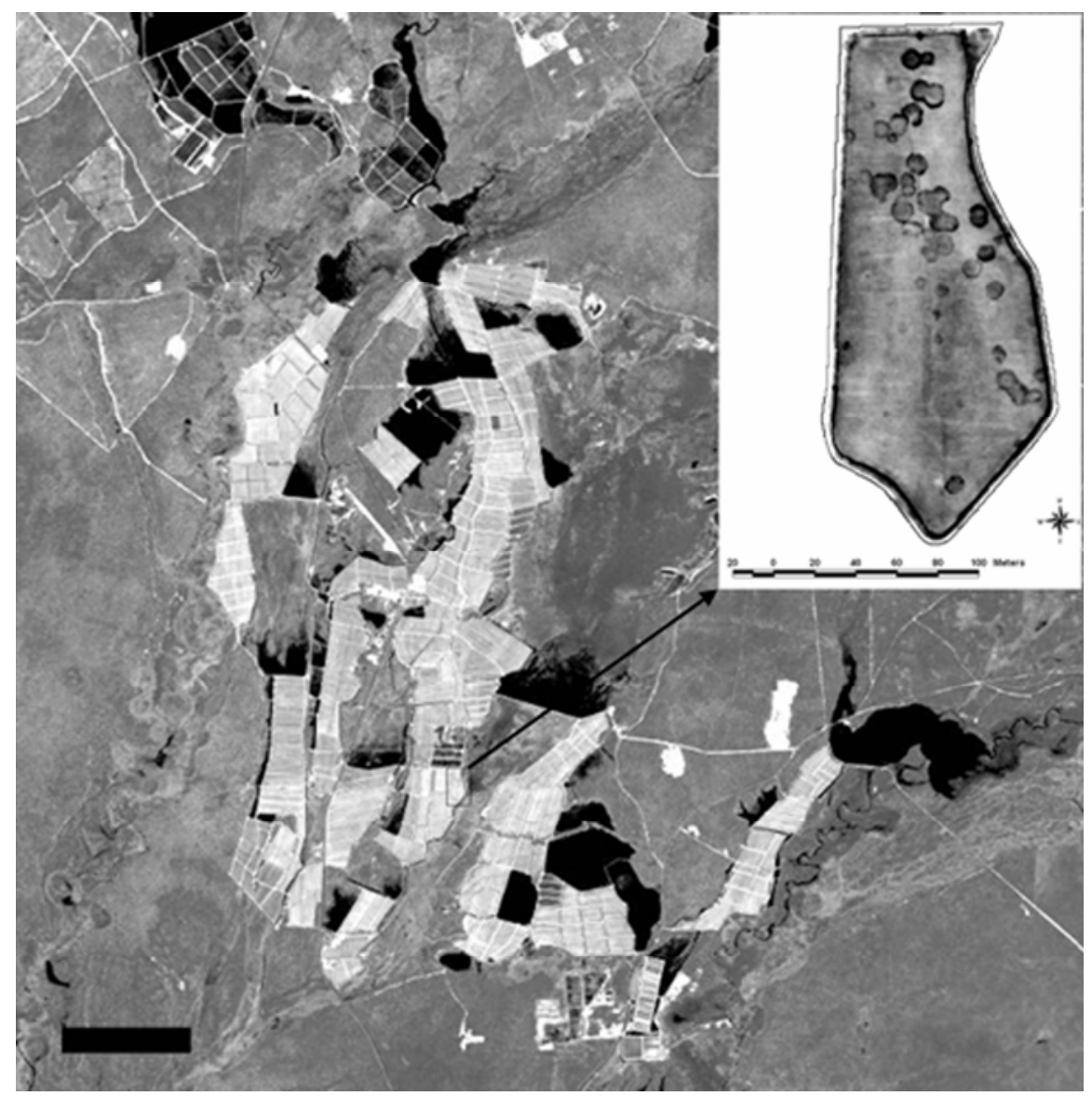

Fig. 2. Example of the panchromatic QuickBird satellite image with a pixel resolution of $0.6 \mathrm{~m}$. The image was taken on 10 July 2005 over the study area. Inset is a subset of the larger image clipped out (location indicated by the arrow) and reprojected to more accurately georeference points. Note that fairy rings (darker rings) are visible in the inset. 
chased from a commercial vendor (Space Imaging, Thornton, CO, or Digital Globe, Longwood, $\mathrm{CO}$ ) and was evaluated for resolution of fairy rings. For imagery with sufficient pixel resolution to identify fairy rings (Table 1), an area of interest was clipped out of the larger imagery (in 2000, 2003 , to 2006) and this subset was georeferenced to the same coordinates as the NIR aerial imagery (Fig. 2). The periphery of each ring as well as field boundaries were entered by digitizing in ArcView (version 3.3; ESRI) using the georeferenced imagery as a backdrop. The area of each digitized polygon (fields and rings) was computed using an Avenue script (calcacre) in ArcView version 3.3.

A subset of 10 rings were selected from the untreated 'Ben Lear' field and used to quantify growth rate. These rings were

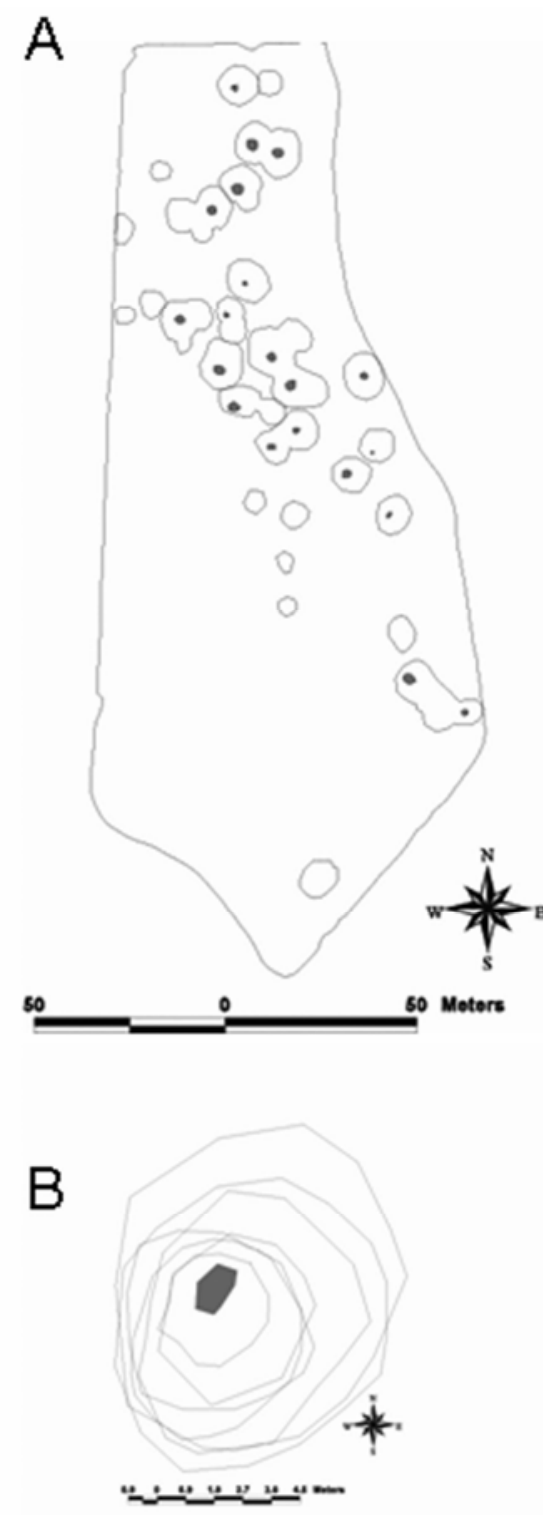

Fig. 3. Digitized fairy rings. A, Incidence of fairy ring on the untreated 'Ben Lear' field where the study was conducted. Smaller solid rings were digitized from 1997 imagery while the larger outlined rings were from 2006. B, Change in ring size from 1997 to 2006. selected because they were detected early in the study period (1997) and did not grow into or merge with other rings. The area and circumference of each ring were calculated, and the radius was estimated from the area using the formula for a circle (radius $=\sqrt{ }[\operatorname{area} / \pi])$. The analysis for increase in radius over time was estimated using simple linear regression $(y=m x+b)$ in the software package CoStat (version 6; CoHort Software, Monterey, CA). In 2006, all fairy rings that could be detected from the panchromatic QuickBird satellite imagery were digitized as detailed above from the entire 675-ha region. These data were overlaid onto a map of digitized cranberry fields and the areas of each ring were determined. This map then was used to identify 180 sampling locations in fairyring-infested fields within the study area.

Ring morphology. In 2001, an intensive sampling of a single ring was conducted in the untreated 'Ben Lear' field. A grid measuring 6 by $7.5 \mathrm{~m}$ was overlaid on the fairy ring and surrounding vegetation. The grid then was divided into 500 cells, each measuring $929 \mathrm{~cm}^{2}$. A total of 274 cells fell $50 \%$ or greater within the ring, and 226 fell $50 \%$ or greater outside of the ring. The grid was georeferenced and the grid cells entered into ArcView version 3.3. All berries were collected from each cell and the weights of healthy and rotted fruit were measured. In addition, for each cell, the percentage of area occupied by dead vines and weed infestation were estimated.

Yield estimation. To estimate yield effects of fairy ring, sampling points were located within diseased areas as well as in adjacent healthy areas in the untreated 'Ben Lear' field. Each point was marked with a flag and georeferenced using a Trimble Pro-XR GPS unit. Yields were estimated by harvesting all the fruit within a $929-\mathrm{cm}^{2}$ square and separating the fruit into sound and rotted categories. Fruit in each category then were weighed. Sampling locations to measure the impact of fairy ring on yield and fruit rot were placed with sufficient distance between them to assume statistical independence (9). In 2006, 180 sampling plots were established inside $(n=90)$ and outside $(n=90)$ of rings in fairy-ring-infested fields across the entire study region. Three cultivars were sampled: Ben Lear $(n=81)$, Early Black $(n=58)$, and Stevens $(n=41)$. Samples were collected and evaluated in the same manner as detailed above. Two-way analyses of variance, with factors location (inside or outside ring) and year (2000, 2004, and 2005) or cultivar (Ben Lear, Early Black, and Stevens) were conducted using Proc MIXED in SAS (version 9.1.3; SAS Institute, Cary, NC) to compare yield and fruit rot between inside and outside ring locations. Heterogeneous within-(location-year) or within(location-cultivar) variances were modeled using the GROUP= option in the Proc MIXED REPEATED statement (5).
DNA isolation and analysis of genetic diversity. To test the hypothesis that the fairy ring disease impacts host genetic diversity, vine samples were collected from affected fields for DNA fingerprinting. Three 'Ben Lear' and three 'Early Black' fields were selected. In each field, 19 to 21 samples (a sample consisted of a single upright) were collected inside the fairy rings (i.e., in disease-affected areas) and 19 to 21 samples were collected outside the rings (i.e., in healthy areas). Leaves were collected from each upright and DNA was extracted using the cetyltrimethylammonium bromide procedure (11) with minor modifications. Samples of leaves $(200 \mathrm{mg})$ were ground in 10-by12.5-cm mesh bags (Agdia, Elkhart, IN) with $2 \mathrm{ml}$ of extraction buffer using a circular bearing tissue homogenizer (Agdia) attached to a drill press. Purified DNA was quantified using a fluorometer (DyNA Quant 200; Hoefer Scientific Instruments, San Francisco). Samples were fingerprinted using the sequence-characterized amplified region (SCAR) method (8). Bona fide 'Ben Lear' and 'Early Black' samples were used as controls.

Genetic diversity estimates, $\hat{H}$, (and their variances, $V(\hat{H}))$ were calculated for each of the 12 fields (i.e., 3 fields for each disease status, healthy $[\mathrm{H}]$ and diseased $[\mathrm{R}]$, and cultivar [Ben Lear and Early Black]) and for each cultivar and disease status by combining the 3 fields therein using Nei (6) and the SAS programming language in the SAS software package (version 9.1.3; SAS Institute). A sample's genetic diversity estimate:

$$
\hat{H}=\frac{n}{n-1}\left(1-\sum_{i=1}^{k} p_{i}^{2}\right)
$$

was defined as the probability that any randomly chosen pair of samples would consist of two different haplotypes, where $n$ is the number of SCAR markers in the sample, $k$ is the number of haplotypes, and $p_{i}$ is the sample frequency of the $i$ th haplotype. Hence, the genetic diversity estimates were based upon the frequency of occurrence of each haplotype in the observed gene copies. The variance of the genetic diversity estimate is obtained by

$$
V(\hat{H})=\frac{2}{n(n-1)}\left\{\begin{array}{l}
2(n-2)\left[\sum_{i=1}^{k} p_{i}^{3}-\left(\sum_{i=1}^{k} p_{i}^{2}\right)^{2}\right] \\
+\sum_{i=1}^{k} p_{i}^{2}-\left(\sum_{i=1}^{k} p_{i}^{2}\right)^{2}
\end{array}\right\}
$$

\section{RESULTS}

Estimation of fairy ring area. Fairy ring areas were measured both on the ground using GPS and from aerial or satellite imagery. The methods corresponded very well; however, imagery had to be georeferenced accurately to provide sufficient correspondence of locations across years, and ring shape often was difficult to measure on the ground. Consequently, 
rings occasionally were missed from ground observation. Not all of the available imagery provided sufficient pixel resolution to accurately identify fairy rings (Table 1). Of the products tested, only the NIR aerial imagery and the QuickBird panchromatic imagery were useful, and both had a $0.6 \mathrm{~m} /$ pixel ground resolution (Fig. 2). The multispectral imagery had lower pixel resolution (2.4 and 4.0 $\mathrm{m} /$ pixel) and was insufficient to identify fairy rings. Aerial NIR imagery was utilized beginning in 1989, and the earliest evidence of fairy ring infection was seen in 1997 in the untreated field. This was 5 years after commercial production began and 8 years after planting. The distribution and change in fairy ring area was quantified over the 10-year period (Fig. 3) using GIS methodologies. The increase in fairy ring area $\left(\mathrm{m}^{2}\right)$ appeared exponential; however, the increase in radius (calculated from the area of a circle) was described using simple linear regression. The average rate of expansion was $0.455 \pm 0.058$ $\mathrm{m} /$ year (Table 2).

Because the fairy rings tended to merge, it was difficult to estimate the increase in disease foci based only on ring numbers. For this reason, individual foci were identified each year and these were enumerated. Rings that merged could encompass as many as four foci that had appeared separately in previous years. There was a linear rise in the number of foci over time (Fig. 4). In 2000 , there were several rings that were not detected using ground-based survey methods; however, they were evident from imagery in both 1999 and 2001. These rings (foci) possibly were missed during the survey and there was no imagery available for 2000. In 2001, in all, 30 foci were mapped. Many of these foci were not apparent in 2003 but were detected again in 2006. This suggests that visibility of established rings will vary from year to year. The total affected area within the cranberry field studied increased exponentially over time (Table 3 ). When the total area was normalized by the number of expanding rings and a radius

Table 2. Change in radius of 10 non-overlapping fairy rings in an untreated commercial field of 'Ben Lear' over a 5- to 8-year period

\begin{tabular}{lccc}
\hline Ring no. & $\begin{array}{c}\text { No. of } \\
\text { years }\end{array}$ & Slope $^{\mathbf{z}}$ & $\boldsymbol{r}^{\mathbf{2}}$ \\
\hline 1 & 7 & 0.474 & 0.996 \\
2 & 8 & 0.546 & 0.980 \\
3 & 8 & 0.504 & 0.981 \\
4 & 8 & 0.426 & 0.958 \\
5 & 7 & 0.477 & 0.991 \\
6 & 6 & 0.340 & 0.977 \\
7 & 6 & 0.505 & 0.960 \\
8 & 5 & 0.437 & 0.958 \\
9 & 7 & 0.436 & 0.986 \\
10 & 6 & 0.412 & 0.954 \\
\hline
\end{tabular}

${ }^{\mathrm{z}}$ Slope represents the change in radius $(\mathrm{m})$ per year. All slopes are significantly different from zero at $P<0.0001$. calculated, a regression line describing increase over time was very similar to the average slope calculated for the 10 individual rings (Table 3 ).

Ring morphology. In 2001, samples were collected from a grid that encompassed one entire fairy ring and the surrounding healthy area. Samples were col-

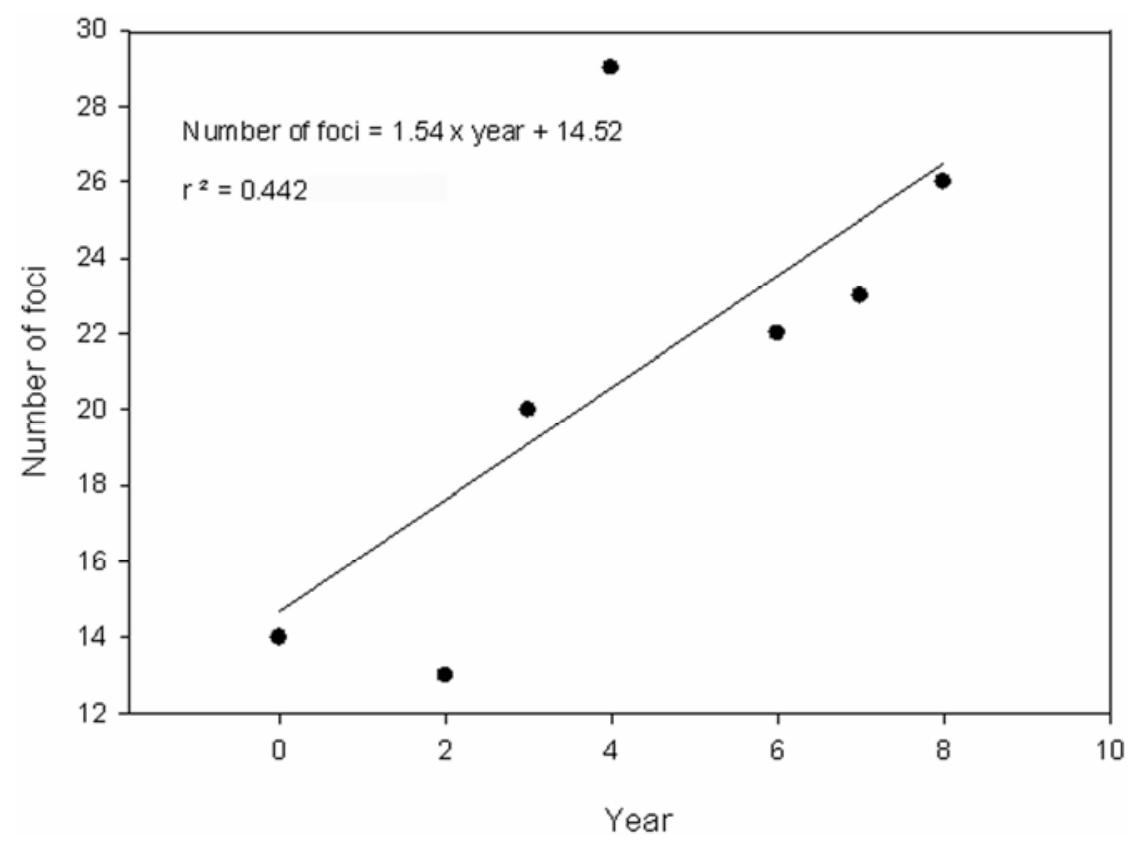

Fig. 4. Change in the number of fairy ring foci over time.

Table 3. Changes in fairy ring incidence and severity over a 10-year period in an untreated field of 'Ben Lear'

\begin{tabular}{lccccc}
\hline Year & $\begin{array}{c}\text { No. of } \\
\text { foci }\end{array}$ & $\begin{array}{c}\text { No. of } \\
\text { rings }\end{array}$ & $\begin{array}{c}\text { Total affected } \\
\mathbf{a r e a}\left(\mathbf{m}^{\mathbf{2}}\right)\end{array}$ & $\begin{array}{c}\text { Average ring } \\
\text { size }\left(\mathbf{m}^{\mathbf{2}}\right)^{\mathbf{y}}\end{array}$ & $\begin{array}{c}\text { Radius } \\
(\mathbf{m})^{\mathbf{z}}\end{array}$ \\
\hline 1997 & 20 & 20 & 71.85 & 3.59 & 1.07 \\
1999 & 21 & 21 & 228.83 & 10.90 & 1.86 \\
2000 & 19 & 19 & 361.09 & 19.00 & 2.46 \\
2001 & 30 & 30 & 678.41 & 22.61 & 2.68 \\
2003 & 27 & 24 & 825.99 & 34.42 & 3.31 \\
2004 & 28 & 26 & $1,127.45$ & 43.36 & 3.72 \\
2005 & 36 & 28 & $1,947.44$ & 69.55 & 4.70 \\
2006 & 41 & 28 & $2,401.48$ & 85.78 & 5.23 \\
Slope $\left(r^{2}\right)$ & $\ldots$ & $\ldots$ & $\ldots$ & $\ldots$ & $0.4406(0.973)$ \\
\hline
\end{tabular}

${ }^{y}$ Average ring size was determined by dividing total infected area by the number of active rings.

${ }^{\mathrm{z}}$ Radius of the rings was calculated from the average ring size using the formula area (circle) $=\pi \times$ (radius) $)^{2}$.

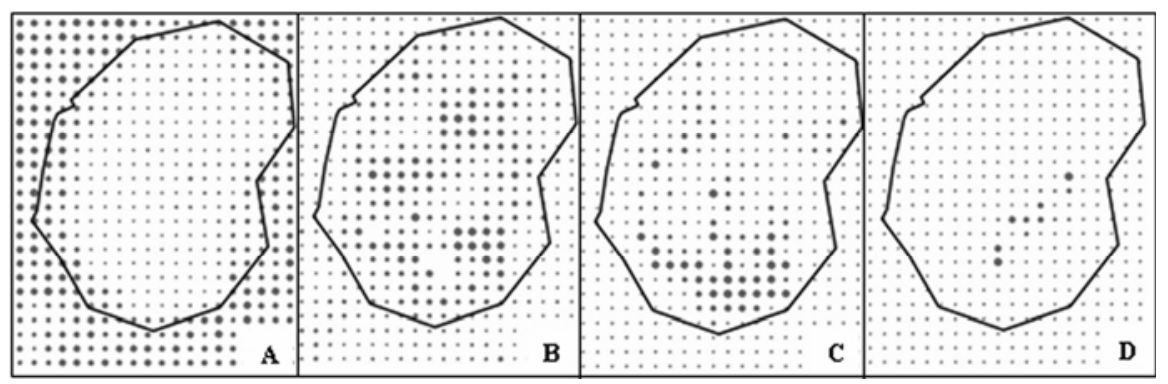

Fig. 5. Data collected from a 500-cell grid placed over a single fairy ring showing the effects on $\mathbf{A}$, yield, $\mathbf{B}$, fruit rot, $\mathbf{C}$, vine death, and $\mathbf{D}$, weed growth. Increasing dot size represents increasing values for each variable. There were 274 samples taken inside the ring perimeter and 226 in healthy vines. A, Average yield inside and outside of the ring was $1,570.8$ and $4,853.6 \mathrm{~g} / \mathrm{m}^{2}$, respectively. B, Fruit rot was elevated inside of the ring (38.0\%) versus outside of the ring (12.8\%). C and D, Distribution of vine death and presence of weeds was limited to within the ring perimeter only. 
cated along the edge of the ring (Fig. 5A). In addition, the distribution of fruit rot, vine die back, and weed invasion were mapped (Fig. 5B, C, and D). These data confirm observations on the distribution of fruit rot, patterns of vine dieback, and the occurrence of weed establishment in areas of vine dieback (Figs. 1 and 2-inset).

Yield estimation. Samples were collected within the boundary of fairy rings and in unaffected areas of the field. Samples were collected over a 4-year period in cv. Ben Lear and demonstrated a significant effect of fairy ring on yield (Table 4).

Table 4. Yield estimate for healthy fruit harvested within the untreated 'Ben Lear' cranberry field over a 3-year period

\begin{tabular}{lccc}
\hline & \multicolumn{3}{c}{ Year } \\
\cline { 2 - 4 } Location & $\mathbf{2 0 0 0}$ & $\mathbf{2 0 0 4}$ & $\mathbf{2 0 0 5}$ \\
\hline Inside Ring $\left(\mathrm{g} / \mathrm{m}^{2}\right)$ & $2,341.2(64)^{\mathrm{y}}$ & $1,387.9(31)$ & $1,539.8(29)$ \\
Outside Ring $\left(\mathrm{g} / \mathrm{m}^{2}\right)$ & $3,005.8(64)$ & $3,997.6(20)$ & $4,009.6(18)$ \\
$P^{\mathrm{z}}$ & 0.0061 & $<0.0001$ & $<0.0001$ \\
Average for field $\left(\mathrm{g} / \mathrm{m}^{2}\right)$ & $2,427.821$ & $3,314.853$ & $4,702.72$ \\
\hline
\end{tabular}

y Number of samples collected to generate each estimate is shown in parentheses.

${ }^{\mathrm{z}}$ Significant difference inside versus outside the rings was determined via a contrast for each year in a two-way location-year analysis of variance modeling heterogeneous variances.

Table 5. Estimate of fruit rot incidence at harvest within the untreated 'Ben Lear' cranberry field over a 3-year period

\begin{tabular}{lccc}
\hline & \multicolumn{3}{c}{ Year } \\
\cline { 2 - 4 } Location & $\mathbf{2 0 0 0}$ & $\mathbf{2 0 0 4}$ & $\mathbf{2 0 0 5}$ \\
\hline Inside ring (\%) & $24.4(64)^{\mathrm{y}}$ & $21.5(31)$ & $29.2(29)$ \\
Outside ring(\%) $_{\text {Significance }}^{\mathrm{z}}$ & $26.7(64)$ & $4.0(20)$ & $14.0(18)$ \\
\hline
\end{tabular}

${ }^{y}$ Number of samples collected to generate each estimate is shown in parentheses.

${ }^{\mathrm{z}}$ Significant difference inside versus outside the rings was determined via a contrast for each year in a two-way location-year analysis of variance modeling heterogeneous variances.

Table 6. Yield estimates taken from inside and outside of fairy rings found on different cranberry cultivars near Chatsworth, NJ, in 2006

\begin{tabular}{lcccc}
\hline Cultivar & $\boldsymbol{n}$ & Yield inside ring $\left(\mathbf{g} / \mathbf{m}^{\mathbf{2}}\right)$ & Yield outside $\mathbf{r i n g}\left(\mathbf{g} / \mathbf{m}^{\mathbf{2}}\right)$ & $\boldsymbol{P}^{\mathbf{z}}$ \\
\hline Ben Lear & 81 & $1,483.1$ & $3,545.8$ & $<0.0001$ \\
Early Black & 58 & $1,399.4$ & $2,123.1$ & 0.0056 \\
Stevens & 41 & $2,098.4$ & $3,233.2$ & 0.0026 \\
\hline
\end{tabular}

${ }^{\mathrm{z}}$ Significant difference inside versus outside the rings was calculated via a contrast for each year in a two-way location-cultivar analysis of variance modeling heterogeneous variances.

Table 7. Fruit rot estimates from inside and outside of fairy rings found on different cultivars near Chatsworth, NJ, in 2006

\begin{tabular}{llccl}
\hline Cultivar & $\boldsymbol{n}$ & Rot inside ring $\mathbf{( \% )}$ & Rot outside ring $(\boldsymbol{\%})$ & $\boldsymbol{P}^{\mathbf{z}}$ \\
\hline Ben Lear & 81 & 18.3 & 6.7 & 0.0015 \\
Early Black & 58 & 8.9 & 4.2 & 0.0168 \\
Stevens & 41 & 3.9 & 2.1 & $0.0799(\mathrm{~ns})$ \\
\hline
\end{tabular}

${ }^{\mathrm{z}}$ Significant difference inside versus outside the rings was determined via a contrast for each year in a two-way location-cultivar analysis of variance modeling heterogeneous variances.

Table 8. Incidence and severity of fairy ring disease on cranberry fields near Chatsworth, NJ in 2006

\begin{tabular}{lcccc}
\hline Cultivar & $\begin{array}{c}\text { Area sampled } \\
\text { (ha) }\end{array}$ & No. of rings & $\begin{array}{c}\text { Area affected } \\
\text { (ha) }\end{array}$ & $\begin{array}{c}\text { Fields affected } \\
\text { (total fields) }\end{array}$ \\
\hline Ben Lear & 49 & 163 & 2.33 & $15(30)$ \\
Early Black & 290 & 105 & 1.88 & $29(165)$ \\
Stevens & 126 & 63 & 0.48 & $12(83)$ \\
\hline
\end{tabular}

cultivars in New Jersey (Table 6). 'Ben Lear' was found to have the highest losses (approximately 60\%), whereas losses in 'Early Black' and 'Stevens' were much less severe (34 and $35 \%$, respectively). Some of the recorded losses were presumed to be due to increases in fruit rot. Low levels of fruit rot were recorded in the healthy areas of all fields assayed. When affected by fairy ring, fruit rot increased 2.7-fold in 'Ben Lear', 2.1-fold in 'Early Black', and 1.8-fold in 'Stevens'; to 18.3, 8.9 , and $3.9 \%$, respectively, of each cultivar's total harvest over the unaffected areas (Table 7). Losses to fruit rot were lower in 'Early Black' and 'Stevens' because, despite the increase due to fairy ring, total rot levels were still low in these cultivars. Of the cultivars assayed, incidence and severity of fairy ring was highest for 'Ben Lear', with half the fields assayed having the disease (Table 8). Severity of the disease as indicated by the total relative area infected and the total number of rings also was highest for 'Ben Lear' (Table 8).

Genetic diversity. There was a high degree of morphological variation in fruit collected within the fairy-ring-affected versus healthy areas of 'Ben Lear' cranberry fields (Fig. 6). Fruit from 'Early Black' fields was variable regardless of fairy ring presence or absence (not shown). To test if the variability seen in 'Ben Lear' fruit was related to vine genotype, we used the SCAR's DNA fingerprinting system described for cranberry (8) to determine genotype diversity. Using this system, 25 markers (loci) were scored for vines from the 'Ben Lear' fields and 32 markers were scored for vines from the 'Early Black' fields (Table 9). The presence or absence of these markers was used to determine the genetic diversity within and between healthy and fairy-ring-affected areas of the fields. The number of haplotypes detected ranged from 1 to 20 . Thus, diversity estimates in these fields ranged from 0 (one genotype present) to 1.0 (all genotypes distinct). The 'Early Black' fields averaged nearly $99 \%$ diversity regardless of status (healthy or infected). In contrast, 'Ben Lear' fields were much more homogeneous within the healthy areas, averaging about $13 \%$ diversity, whereas fairy ring areas had increased overall diversity of about $57 \%$ (Table 9).

\section{DISCUSSION}

Shear et al. (10) described fairy ring as a minor disease that manifested in older cranberry fields. No distinctions were made regarding cultivar, and spread was documented at 0.30 to $0.45 \mathrm{~m}$ in radius per season. Caruso (1) cited this observation on the rate of fairy ring expansion; however, no further data has been reported for this disease. Growth rates, determined over a 10-year period in the current study, showed the rate of ring expansion to be 0.34 to $0.55 \mathrm{~m} /$ year in 'Ben Lear'. This 
growth rate was determined by calculating the radius of each ring yearly, with the assumption that the shape of a ring is close to a circle. A second question addressed the rate of formation of new rings. The total number of rings could not simply be counted each year because, as rings merged, the number of apparent infection foci declined. Therefore, each ring was assigned a separate focal point in the year it first appeared and these were tracked over the period of study. The slope of the plot of year versus number of foci gave the average number of new foci formed per year. In this study, it was determined that two to three new ring foci formed per year in a cranberry field with no fairy ring management program. This is the first estimate on the rate of spread for this disease. However, this is likely to be affected by the presence and amount of inoculum, the number of active foci, and local conditions for infection initiation and spread.

In the area covered by satellite imagery, there were approximately 675 ha planted with cranberry in 278 individual fields, and 56 of these were affected by fairy ring. There was a threefold greater likelihood of finding a symptomatic field of 'Ben Lear' than either 'Stevens' or 'Early Black'. In addition, the severity in 'Ben Lear' (i.e., the summed area of rings) also was much greater. 'Early Black' is one of the oldest cultivars grown in New Jersey and some commercial fields were planted during the nineteenth century. 'Ben Lear' was released as a cultivar in 1901; however, plantings in New Jersey did not begin until the 1970s. 'Stevens' was released as a cultivar in 1950, and plantings in our study area were started in the 1980s. Thus, if time were the only factor affecting distribution of fairy ring, one would assume that 'Early Black' should show greater incidence than 'Ben Lear'. Thus we speculate that 'Ben Lear' is more susceptible. It also is possible that fairy ring was previously present on 'Early Black' but the incidence and severity of the disease declined over time.

In comparing symptomatology, it was noted that the necrotic zone is much more defined in 'Ben Lear' than in 'Early Black', where ring margins were more diffuse. This could be partly because the 'Early Black' fields in our study were very genetically heterogeneous, as indicated by the number of genotypes in the healthy areas of the field. The vines in these 'Early Black' fields may have varying natural reactions to the pathogen that moderate the overall response. In fact, the high levels of genetic diversity observed in the old 'Early Black' fields could be due, in part, to previous fairy ring infestations. The 'Ben Lear' fields, in contrast, are much more genetically homogeneous. Thus, if the most common genotype in the 'Ben Lear' fields is susceptible to the pathogen, it is not surprising that the disease is more severe and results in larger open areas in the field. It is plausible that, in the open areas, conditions exist that promote fruit rot and formation of a seed bank. Ultimately, the seed germinate and seedlings become established. Because the seedlings are genetically variable and are probably horticulturally inferior to the parental genotype (i.e., true 'Ben Lear'), increasing genetic diversity corresponds with decreasing yield, contributing to a long-term, negative impact on field production.

Fairy ring caused significant reductions in yield and increases in fruit rot compared with areas unaffected by the disease. In 'Ben Lear', yield reductions were in the range of 22 to $68 \%$ of the unaffected areas. Thus, fairy ring is capable of causing sig-

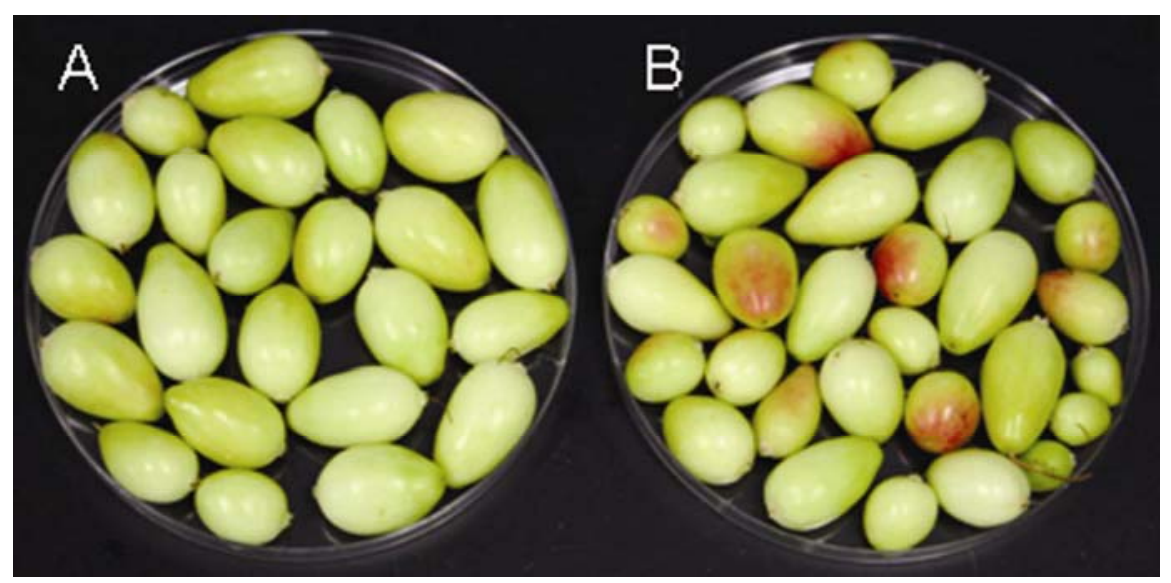

Fig. 6. Fruit variation in 'Ben Lear'. A, Fruit from the healthy areas in a 'Ben Lear' field is typically uniform in size, shape, and phenology, such as ripening time. B, Fruit from fairy-ring-affected areas tends to be variable.

Table 9. Genetic diversity in fairy-ring-affected 'Ben Lear' and 'Early Black' cranberry beds

\begin{tabular}{lccl}
\hline Cultivar, bed & Status $^{\mathbf{w}}$ & No. of haplotypes $^{\mathbf{x}}$ & Diversity estimate (standard error) $^{\mathbf{y}}$ \\
\hline Early Black & & & \\
1 & $\mathrm{H}$ & 17 & $0.981 \mathrm{BC}(0.0044)$ \\
2 & $\mathrm{H}$ & 17 & $0.988 \mathrm{~B}(0.0049)$ \\
3 & $\mathrm{H}$ & 17 & $0.976 \mathrm{C}(0.0052)$ \\
1 & $\mathrm{R}$ & 14 & $1.000 \mathrm{~A}(0.0036)$ \\
2 & $\mathrm{R}$ & 18 & $0.953 \mathrm{D}(0.0084)$ \\
3 & $\mathrm{R}$ & 45 & $0.981 \mathrm{BC}(0.0050)$ \\
\hline \multirow{2}{*}{ Overall } & $\mathrm{H}$ & 47 & $0.9891 \mathrm{Z}(0.00067)^{\mathrm{z}}$ \\
& $\mathrm{R}$ & & $0.9887 \mathrm{Z}(0.00078)^{\mathrm{z}}$ \\
\hline
\end{tabular}

\begin{tabular}{llrl}
\hline Ben Lear & & & \\
1 & $\mathrm{H}$ & 3 & $0.195 \mathrm{D}(0.026)$ \\
2 & $\mathrm{H}$ & 3 & $0.195 \mathrm{D}(0.026)$ \\
3 & $\mathrm{H}$ & 1 & $0.000 \mathrm{E}(0.000)$ \\
1 & $\mathrm{R}$ & 7 & $0.584 \mathrm{~B}(0.029)$ \\
2 & $\mathrm{R}$ & 11 & $0.805 \mathrm{~A}(0.021)$ \\
3 & $\mathrm{R}$ & 4 & $0.271 \mathrm{C}(0.028)$ \\
\hline Overall & $\mathrm{H}$ & 3 & $0.129 \mathrm{Y}(0.0076)^{\mathrm{z}}$ \\
& $\mathrm{R}$ & 16 & $0.569 \mathrm{Z}(0.0099)^{\mathrm{z}}$ \\
\hline
\end{tabular}

w Vine status is noted as healthy $(\mathrm{H})$ or from diseased (R) areas.

${ }^{x}$ Number of haplotypes are the number of different genotypes based on sequence-characterized amplified region DNA fingerprinting. Total number of samples per field for each status ranged from 19 to 21 .

${ }^{y}$ Diversity estimate is the probability that any randomly chosen pair of samples will consist of two different haplotypes (6) and is calculated based on the observed frequency of each unique haplotype in the samples. Estimates were calculated for each individual bed. Diversity estimates for each bed of a specific cultivar with the same letter are not statistically different $(\alpha=0.05)$. The overall diversity for each bed status ( $\mathrm{H}$ or $\mathrm{R}$ ) was calculated from the combined data for that particular cultivar.

${ }^{\mathrm{z}}$ For each disease status, diversity estimates with the same letter are not statistically different $(\alpha=0.05)$. 
cover, thus increasing competition for resources. Assessment of indirect losses are much more problematic and possibly of greater significance. Increased levels of fruit rot may lead to increased genetic diversity by promoting seedling establishment. The longevity of a cranberry planting is dependent upon sustained productivity, and increased genetic diversity, in particular, can reduce long-term yield potential. Replanting cranberry as a result of changes in the genetic composition of the crop may be the most economically significant aspect of this disease.

\section{LITERATURE CITED}

1. Caruso, F. L. 1995. Fairy ring. Pages $47-48$ in: Compendium of Blueberry and Cranberry Diseases. F. L. Caruso and D. C. Ramsdell, eds.
American Phytopathological Society, St. Paul, $\mathrm{MN}$.

2. Chang, Li-Ping. 1989. Fungi associated with fairy ring and dieback of cranberry Vaccinium macrocarpon: histopathology and pathogenicity. M.Sc. thesis, Department of Plant Pathology, Rutgers University, New Brunswick, NJ.

3. Hlubik, W. T. 1988. A species of Phialophora associated with fairy ring and dieback on cranberry. M.Sc. thesis, Department of Plant Pathology, Rutgers University, New Brunswick, NJ.

4. Kesecker, K. 2004. U.S. Cranberry, Fruit and Vegetable Programs, AMS, U. S. Dep. Agric. www.cranberrries.org/pdf/us_cran_crops.pdf.

5. Littell, R., Milliken, G., Stroup, W., Wolfinger, R., and Schabenberger, O. 2006. SAS for Mixed Models, Second Edition. SAS Institute Inc., Cary, NC.

6. Nei, M. 1987. Molecular Evolutionary Genetics. Columbia University Press, New York.

7. Oudemans, P. V., Constantelos, C., Wasilwa,
L., Polashock, J., Caruso, F. V., and Carris, L. M. 2002. Identification of the causal agent of fairy ring disease on cranberry. (Abstr.) Phytopathology 92:S61.

8. Polashock, J., and Vorsa, N. 2002. Development of SCAR markers for DNA fingerprinting and germplasm analysis of American cranberry. J. Am. Soc. Hortic. Sci. 127:677-684.

9. Pozdnyakova, L., Gimenez, D., and Oudemans, P. V. 2005. Spatial analysis of cranberry yield at three scales. Agron. J. 97:49-57.

10. Shear, C. L., Stevens, N. E., and Bain, H. F. 1931. Fungous diseases of the cultivated cranberry. U.S. Dep. Agric. Tech. Bull. 258.

11. Stewart, C. N., and Via, L. E. 1993. A rapid CTAB DNA isolation technique useful for RAPD fingerprinting and other PCR applications. Biotechniques 5:748-750.

12. Zuckerman, B. M., Rochefort, K. J., and Rounsville, G. B. 1968. Control of fairy ring disease of the cultivated cranberry. Plant Dis. Rep. 52:87-88. 